\title{
Sensory Branding: \\ A Pilot Study of the Effect of Sensory Value on Branding in Electronic Word of Mouth (eWOM)
}

\author{
By Brenda Saris ${ }^{*}$
}

The purpose of this paper is to examine the effects of sensory value on branding as described through eWOM in social media through an experimental design that crosses valence (intrinsic appeal, positive or negative) with six branded products. The study considers relationships between the five human senses (sight, touch, taste, smell and sound), utilitarian/rational and hedonic/emotional brand appeals, and brand loyalty. Results indicate that the mean effect of valence from all senses for utilitarian/rational brands have registered highly significant statistical difference between the baseline question, positive and negative reinforcement. This result is different for hedonicl emotional brands. Participant response from all five senses did not become more positive when a positive emotional eWOM opinion from a friend was posted online. Key elements emerge which consider emotional and subjective capabilities of the customer, which in turn may enable business to stay competitive in the shifting landscape of humanistic branding.

Keywords: brand loyalty, branding, eWOM, senses, subjectivity

\section{Introduction}

Creating value for customers is about creating multisensory and multidimensional experience, to which they will respond with trust and loyalty. Brand value is significantly grounded on emotions that are activated through the five human senses with successful brand strategies designed to convey meaningful experience to the five senses to elicit and trigger buying behaviors. However, designing for the five senses is largely forgotten when brand strategies are devised for social media. Although one could draw conclusions based on assertions that powerful branding and loyalty is built on all five senses and the more sensory bonding components in a brand, the stronger the foundation (Lindstrom, 2005, p. 111), designing for them online appears problematic. People lose intangible aspects of customer experience, such as atmosphere or the subtleties of face-to-face interactions (Murray, 2003, p. 7). Whilst it is possible to see and hear things online, there is limited opportunity for a customer to interact with products, feel weight or experience tactile aspects. Vachon (2011) contends that taste, smell and touch cannot be experienced virtually and Yohn (2013) argues that firms need to enrich sensory experience, but the web does not allow users to taste or smell products (p. 128).

These apparent issues are at odds with sensory branding theory which advocates the benefit of strategies such as "sense layering" to command and

${ }^{*}$ Researcher/Senior Lecturer, Whitireia, New Zealand. 
strengthen emotional response to brands (Clark, 2004, p. 81; Post, 2004, p. 105). Or, that creating brand loyalty is achieved by designing sensory consistancy (Lindstrom, 2005, p. 115). The shortfall of these theories is that they fail to acknowledge that marketing channels for brand communications are different, although some argue that social and traditional media are inextricably linked, although nuanced which leads to managerial implications (Powell, Groves \& Dimos, 2011, p. 79). Some brands may possess a greater number of possible opportunities for sensory branding in social media as they contain readily obvious cues. For example, headphones relating to sound or images of fashion brands connecting to appearance on a model. These types of brands may be determined as emotional or hedonic as they potentially incite positive intrinsic appeals. But what about less alluring brands such as products associated with work, for example a stapler? How can a strategist impart sensory brand appeals about utilitarian or rational brands in social media? Therefore, what are the effects of sensory value on branding as described through eWOM in social media, and to what effect does this reflect on brand loyalty? The literature in this area is limited as studies relating to sensory branding mostly refer to offline scenarios; the aim of this pilot study is to explore sensory branding in order to shed light on the impact of eWOM.

\section{Literature Review}

\section{Brand Loyalty and Electronic Word of Mouth (eWOM) in Social Media}

Establishing online credibility and loyalty is increasingly complex for companies. Much of the literature identifies that brand loyalty is achieved by creating emotional, desirable and memorable brand experience for customers and that the repetition of leveraging these underlying appeals is the bedrock of building brand equity (Blackett, 2003, p. 18; Jung \& Soo, 2012; Neumeier, 2007; Peters, 2003). Whilst undeniably still relevant, most of the literature refers to off-line scenario's and traditional marketing techniques.

"Social media sites already offer great opportunities to engage with and influence customers in ways that are different from traditional marketing approaches"

(Brown, 2012, p. 14).

Customers use social media to express brand preference, with recent studies highlighting the momentum of increased use of electronic word of mouth (eWOM) directly relating to customer loyalty, brand reputation and attachment (Chiou, Hsu \& Hsieh, 2013; Vachon, 2011; Wu \& Wang, 2011).

Fundamentally, social marketing strategies support the notion of listening then engaging with influencers, individuals and customers in order to move customers down the "purchase funnel" to stimulate product purchase, and later brand loyalty for repeat purchase (Powell, et al., 2011, p. 10). Previous studies supported building brand loyalty in social media through controlled online communities of "real people" who are in fact, company people (Ha, 2004). 
There are many tools to measure the success of these strategies, with advancing technological methodologies designed to tap into web conversations (Harden \& Heyman, 2009, p. 97; Powell, et al., 2011, p. 93). However, Schultz and James (2013) cautions against marketers desires to leverage social media for advantage by stating the web is social in that it links people in collective conversational webs, not to sell branded products. Social conversations are expressed through eWOM which typically occurs in an anonymous online environment (Lin, Lu \& Wu, 2012; Wu \& Wang, 2011). As a result, customers may doubt the credibility of eWOM information.

When in doubt, customers prefer to delegate the decision-making process to trusted opinions from reliable sources. Word of mouth (WOM), is well recognised as a powerful form of recommendation by individuals (Harden \& Heyman, 2009, p. 98; Lepkowska-White, 2013; Vachon, 2011). 92\% of customers trust WOM, and $70 \%$ trust user generated-content, more than any other form of advertising, social media or email marketing (Guzman \& Iglesias, 2012, p. 388). Customers use eWOM to discuss companies and brands without prompting, and potentially create purchase intent (Gerson 1998, p. 76; Pradeep \& Meerman 2010, p. 117). eWOM in social media becomes valuable social currency (Oatway, 2012, p. 11). In addition to eWOM, Chiou et al. (2013) found that individual brand attachment can reduce the effects of negative online information and that the severity of negative online information may be moderated by the credibility of the source. Wu and Wang (2011) go slightly further by suggesting that although message source credibility is an important factor which may influence purchase intent, customers with a high degree of product involvement will defer to rational over emotional appeal, whereas a low product association observes less significant difference between rational and emotional appeals.

The distinction between rational and emotional appeals in conjunction with eWOM is relevant to the study objectives because material phenomena are perceived, assessed and privileged through the five senses. The five senses form part of a value chain for the customer. Potentially, as per sensory branding theory, brand loyalty may be created through layering of the senses to command and strengthen emotional response to brands within social media (Clark, 2004, p. 81; Lindstrom, 2005, p. 115; Post, 2004, p. 105).

\section{Evoking the Senses and Subjectivity in Social Media}

How does brand strategy design for stimulation of the senses not catered for in social media, such as smell and taste? Of the few studies related to eWOM and sensory value, Lin et al. (2012) sought to rectify how little was known about visual information affecting consumer perception and purchase intention in eWOM content, by contending that most previous studies focus on verbal content. Their findings suggested that imagery evoked by visuals may offer a sensory substitute, potentially adding further dimension to a brand experience when a customer is interacting with brands online (Clark, 2004, pp. 67-81; Lin et al. 2012). Dooley (2011) describes how a barbeque sauce brand 
used visual and sound stimuli to evoke imprints that then enabled the customer to smell and taste the barbeque experience "right through the glass on the TV screen" (p. 101). Although written eleven years ago, it could be argued that this concept is more pertinent now than ever, due to the increasing amount of screen time experienced by society today.

Evoking the memory of a sense through imagery or sound within a technological environment may be developed in two specific ways. From very concrete (explicit) appeals to the senses to more abstract (implicit) ideas and deeply embedded emotional memories. Memories associated with taste and smell, are not filtered out by the brain, but rather instinctive and involuntary (Gobé, 2009, p. 99). Also instinctive is intangible sensation. The stimulus for sensations or feelings may come from the inside or outside of the individual (Goody, 2002, p. 17). Siegel (2013) claims that the first part of a sensory experience is an experience in which "raw feels", or sensory affectations of the subject, do not purport to represent the world in any way at all. The second part is a version of adverbialism, relating to experiences, which may be nothing more than modifications of a subject. This may be characterized by specialized adverbs specifying the phenomenon. This suggests that when describing the intangible, individuals may resort to subjectivity, but the connection between the senses and our brain is direct. Meaning branding within social media may be designed to appeal directly to the emotions and stored memories of customers (Dooley, 2011, p. 35).

Defining subjectivity in relation to the five senses is difficult, as exemplified by Nagel's "what it is like" theories which aimed to capture a subjective notion of being a conscious organism (Nagel, 1995; Van Gulick, 2014). Nagel (1995) best describes this, as "everything in the world is equally real - from my sense impressions to the stars - but still the world is my world" (p. 47). In other words, because we use language to describe what it is like, what we see, smell, hear, taste or feel, the description becomes a personal and subjective worldview which makes it real to the individual. This presents challenges for brand designers/photographers' who are conceptualising, or shaping desired meanings. Their subjective assessment and intent may not communicate successfully with an intended target audience, because an individual would rather project their own subjective assessment onto the image.

\section{Sensory Brand Appeals: Rational and Emotional}

According to Verhagen, Boter and Adelaar (2010) the main difference between utilitarian (rational/objective) and hedonic (emotional/subjective) products lies in their function (p. 142). Utilitarian products perform instrumental or informational functions whereas hedonic products are transformational and may elicit sensory stimulation, emotions, fantasy's and pleasure (Vachon, 2011; Verhagen et al. 2010, p. 142; Wu \& Wang, 2011). This distinction between characteristics is important because hedonic products are evaluated holistically, the result of emotional connections whereas utilitarian products rely on rational information (Verhagen et al. 2010, p. 143). 
Wu and Wang (2011) suggested consumption experience consists of hedonistic and utilitarian elements, but it is emotional appeal that elicits positive or negative emotions. This draws on Morillo's (1990, p. 173) reward effect theory, and a more recent study which defined the two main dimensions of emotion: emotional arousal (calm versus excited) and valence (positive versus negative) (Briefer, Maigrot, Mandel, Freymond, Bachmann, \& Hillmann, 2015).

As a branded product is unable to express itself as being positive or negative an assessment of the influence of valence is not possible. However it is contestable that an individual may relay an expression of positive or negative valence in relation to an emotional experience with that product regardless of it being hedonic or utilitarian. Therefore the implication is that both hedonic and utilitarian product experience maybe influenced by valence, but that hedonic/emotional products are more likely to elicit sensory brand appeals because there is more potential to arouse emotion or elicit emotional memory. But how does this effect manifest through eWOM within social media and is brand loyalty likely to be influenced as a consequence? The possible effects of sensory value on branding as expressed through eWOM within the context of social media have very limited coverage. The five senses are the means by which material phenomena are perceived, assessed and privileged, yet in the context of branding in social media, the relevance of sensory value appears to be almost inconsequential.

\section{Research question: How does eWOM effect sensory value in relation to brands?}

\section{Method}

\section{Participants, Design and Procedure}

Designed as a pilot study, participants were a convenience sample comprised of 27 volunteers. The age range spanned 18-55 years and was comprised of 16 males and 11 females (A1. Table 1: Participant Groups). The prospective participants were invited to take part in the study, and once provided with a study information sheet and given the opportunity to ask questions, provided written informed consent. Ethics was approved by the Auckland University of Technology, AUTEC Reference number 13/322. The participants were divided into three separate focus groups. The groups comprised of:

1. Students from architecture, communications, commerce, humanities and law faculties.

2. Designers employed in web/interactive, graphic/brand, illustration, fashion and product design companies.

3. Customers employed in marketing, administration, law and 
government.

Opinions where sought from a series of focus groups and tested through simple subjective assessments (cross-sectional quantitative questionnaire). The advantage of using a cross-sectional survey for this study was that it enabled a quick collection of data at the time of the focus groups, and it allowed identification of attributes from a small group of individuals.

This was an experimental design that crosses valence (positive or negative intrinsic emotional appeal) with six branded products. Participants were introduced to six brands within the focus groups, with the questionnaire distributed to gauge opinions and reactions to different scenarios, and the impact of eWOM. The brands were discussed randomly in order to remove any preconceived bias, but for analysis were grouped thus:

1. Utilitarian/rational.

2. Wilcox potatoes/Raid fly spray/Rapid stapler.

3. Hedonic/emotional.

4. Nike shoe/Sony headphones/Versace fragrance for him or her.

Branded products were chosen which exemplified those used in everyday life and to determine how subjective responses may provide insight into brand strategy. The products were grouped in the analysis to examine how sensory relationships or other factors might be inferred between rational and emotional brands, and to examine the influence of valence. For example the flyspray may be considered as a rational response to an annoying pest (negative issue) a stapler might be representative of work. The potato brand is a staple ingredient and offered potential into brand recognition. Nike is a brand that holds powerful global and local cachet. Therefore a Nike shoe was compared with Sony headphones to understand how a powerful brand might compare to another well known branded product associated with a strong sense experience (sound). Likewise the branded fragrance offered potential for insights into emotional (romantic) brand recognition associated with smell. Conjecture explored additional questions such as, if there was a preconceived understanding about a particular brand, which of the senses were most associated with the brand, or, if the brand was unknown, or lesser known, which of the senses do people access first?

\section{Measures}

The questionnaire was designed to include a seven point Likert scale in order to measure participants attitudes in a succinct (although also subjective) way and enabled a hierarchy (1 23 negative, 4 neutral, 567 positive) to be located (A2. Figure 13. Questionnaire design).

The simple subjective assessment tested the eight branded products firstly, with a base question about the branded product. What is this product? How would you describe this (brand) by: sight, sound, touch, taste and smell. The 
question was not intended to impose an opinion (belief or purpose) and was intended to be as non-prescriptive as possible, in order to locate a baseline objective opinion about the product. It considered how the five senses might be influenced through lived experience, irrespective of branding or social media.

The second question inferred a positive opinion about that branded product. In your opinion this is the best (product) brand. You post a picture of (product made into something, or you interacting with the brand), comments from your friends validate your opinion. How would you describe this (brand) by: sight, sound, touch, taste and smell. The participants were asked to imagine their own interaction with social media through posting a picture or commenting about something they had done with that branded product (for example, Nike shoes are my favourite running shoes, I love feeling the wind in my hair, or the Rapid stapler is the most reliable and therefore the best stapler). The prediction was that those who engage in eWOM might move to be more positive in their view when positive feedback was received from social media contacts (friends). This might suggest that when friends agree with that subjective view, the belief about the brand is reinforced and therefore the same senses might be implicated. At this stage it was less clear how those who do not engage with social media might react, because familiarity with social media was unknown when the questionnaire was designed. Therefore, which senses might be implicit when people are not socialising in an online environment?

The third question was designed to suggest that the participant might doubt their previously formed positive opinion when faced with negative online feedback. You post a picture of (product made into something, or you interacting with the brand), comments from your friends make you doubt your opinion. Describe this (brand) by: sight, sound, touch, taste and smell. This explored the strength of subjectivity when the participant was asked to doubt their opinion, and emotional memories relating to the five senses associated with that brand were challenged. The prediction was that the scale would move in the opposite direction from the response supplied in question two if the participants engaged with eWOM. The information supplied might also offer insight into which of the senses people refer to in order to provide an opinion. Do they go more to taste and smell when talking about the negative, and sight and sound for the positive? The prediction was that the lived experience might connect memory and emotion to a particular sense or group of senses, which relate most readily to a particular product, for example, sound to headphones.

\section{Results}

The dataset was analysed through a paired T-test with significance level set at $\mathrm{p}<0.05$. Key for the results: baseline question (B.Q), positive reinforcement question (P.Q) negative reinforcement question (N.Q).

There was a significant difference between the change in all senses for both rational and emotional brands following negative valence P.Q-N.Q $(0.45 \pm 0.725$ vs $0.67 \pm 0.796, p<0.001)$. Sight was significantly affected by 
change for both rational and emotional brands following positive B.Q-P.Q $(0.63 \pm 0.715$ vs $0.96 \pm 0.798, p=0.006)$ and negative P.Q-N.Q $(0.69 \pm 0.801$ vs $1.09 \pm 0.809, p=0.002)$ valence. Two senses were significantly affected by rational and emotional brands following negative valence P.Q-N.Q. These were touch $(0.47 \pm 0.776$ vs $0.73 \pm 0.775, p=0.035)$ and smell $(0.28 \pm 0.553$ vs $0.75 \pm 0.969, p<0.001)$. However, only taste was found to be affected by rational and emotional brands following positive valence B.Q-P.Q $(0.74 \pm 0.818$ vs $0.33 \pm 0.522, p<0.001$ ).

The mean effect of valence on all senses from utilitarian/rational brands, have registered highly significant statistical difference between B.Q and P.Q (3.85 \pm 1.323 vs $4.05 \pm 1.417, p<0.001$, Figure 1$)$, and P.Q and N.Q (4.05 \pm 1.417 vs $3.71 \pm 1.507, p<0.001$, Figure 1). This result is different from the effect of valence from all senses for hedonic/emotional brands. Highly statistical difference was found only between P.Q and N.Q (4.40 \pm 1.221 vs $3.81 \pm 1.291$, $p<0.001$, Figure 2). There was little difference found between B.Q and P.Q $(4.31 \pm 1.333$ vs $4.40 \pm 1.221, p=0.055$, Figure 2$)$, therefore participants were not found to become more positive when a positive emotional eWOM statement from a friend was posted, however they were influenced by the effect of negative valence from all the senses for hedonic/emotional brands.

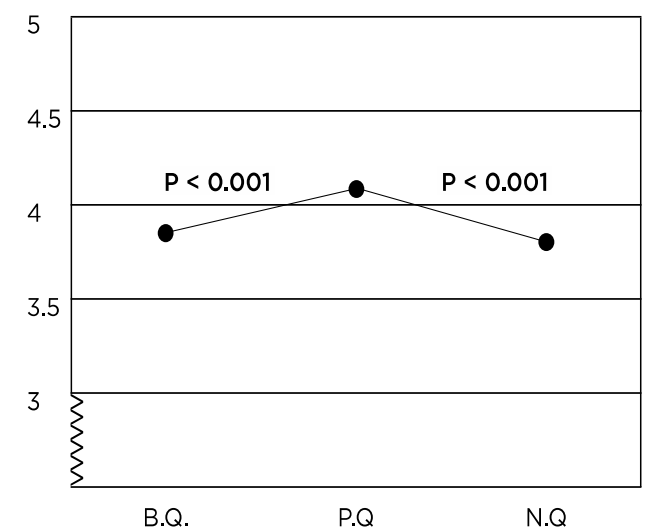

Figure 1. Mean effect of valence from utilitarian / rational brands.

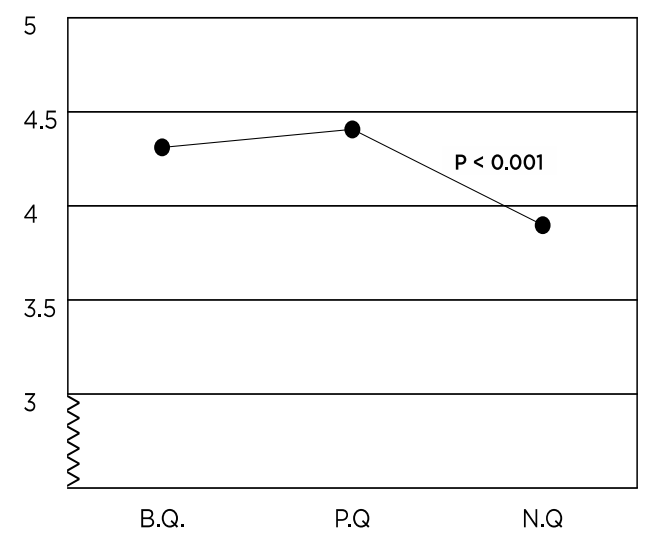

Figure 2. Mean effect of valence from hedonic / emotional brands.

Both sight and smell have registered highly significant statistical difference between B.Q, P.Q and N.Q for both utilitarian/rational brands and hedonic/emotional brands (Figures 3-4 and Figures 11-12). Of the other three senses: touch, taste and sound, only one sense relating to hedonic/emotional brands registered highly significant statistical difference. This was touch, B.QP.Q (4.65 \pm 1.027 vs $4.90 \pm 1.032, p=0.007$, Figure 6), P.Q-N.Q (4.90 \pm 1.032 vs $4.27 \pm 1.194, p<0.001$, Figure 6). Taste and sound registered no difference from hedonic/emotional brands (Figures 8 and 10). With regards to utilitarian/rational brands, touch was found to have no difference (Figure 5), but taste B.Q-P.Q $(3.62 \pm 1.463$ vs $4.11 \pm 1.725, p<0.001$, Figure 7$)$, P.Q-N.Q $(4.11 \pm 1.725$ vs $3.60 \pm 1.648, \quad p<0.001$, Figure 7) and sound B.Q-P.Q 
$(4.43 \pm 1.573$ vs $4.26 \pm 1.571, p=0.005$, Figure 9), P.Q-N.Q (4.26 \pm 1.571 vs $4.06 \pm 1.784, p=0.002$, Figure 9) registered highly significant statistical difference.

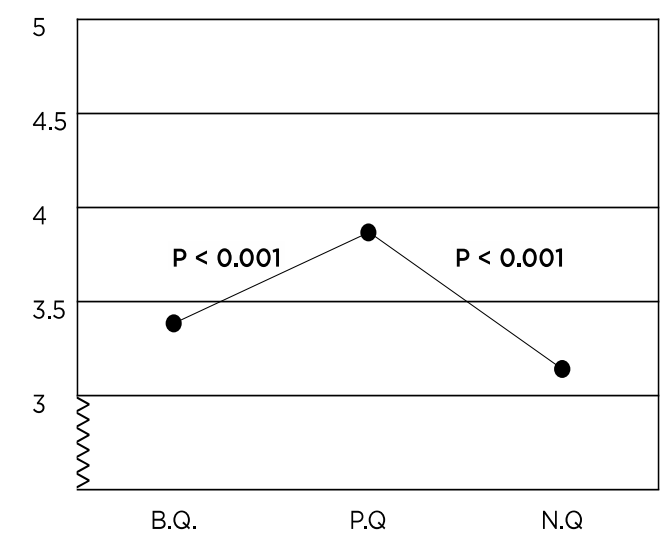

Figure 3. Mean effect of valence on sight from utilitarian / rational brands.

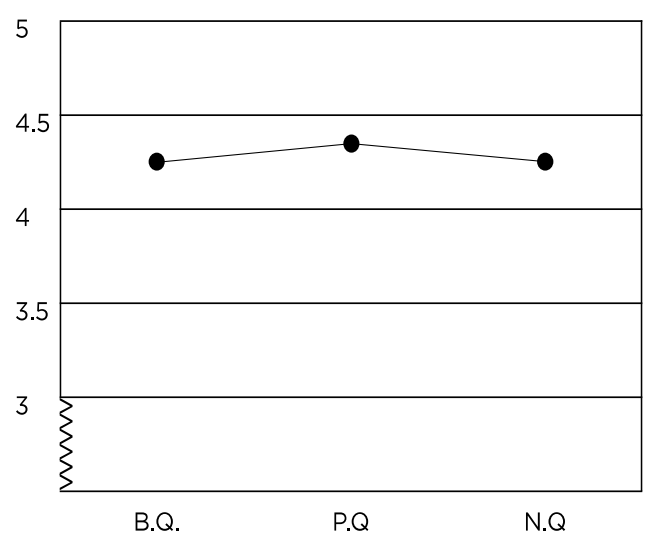

Figure 5. Mean effect of valence on touch from utilitarian / rational brands.

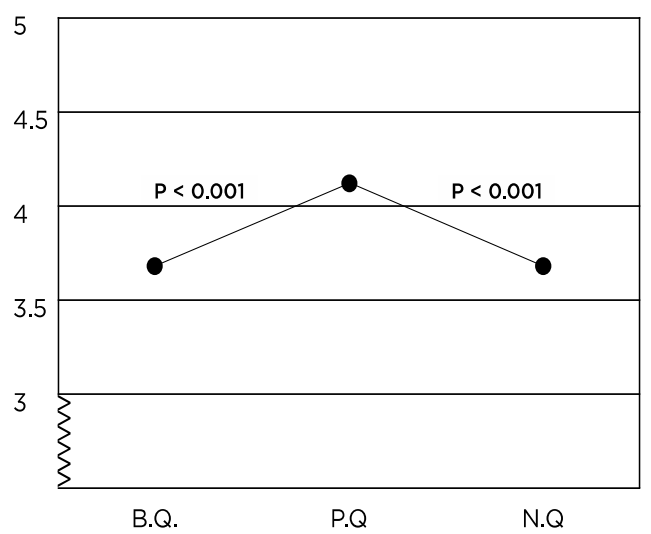

Figure 7. Mean effect of valence on taste from utilitarian / rational brands.

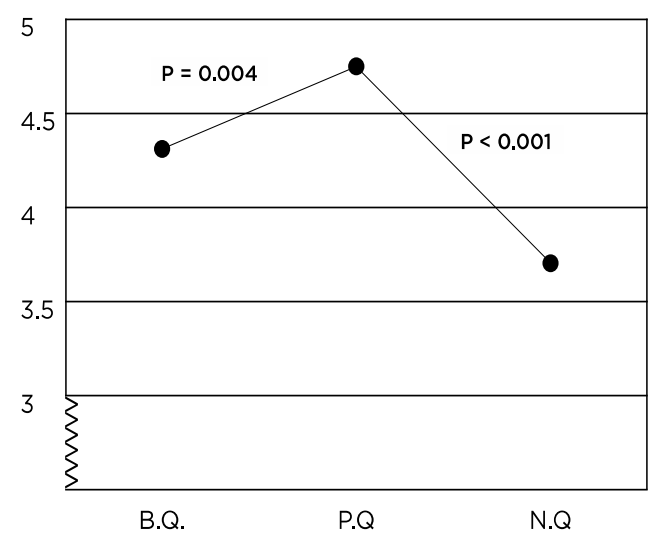

Figure 4. Mean effect of valence on sight from hedonic / emotional brands.

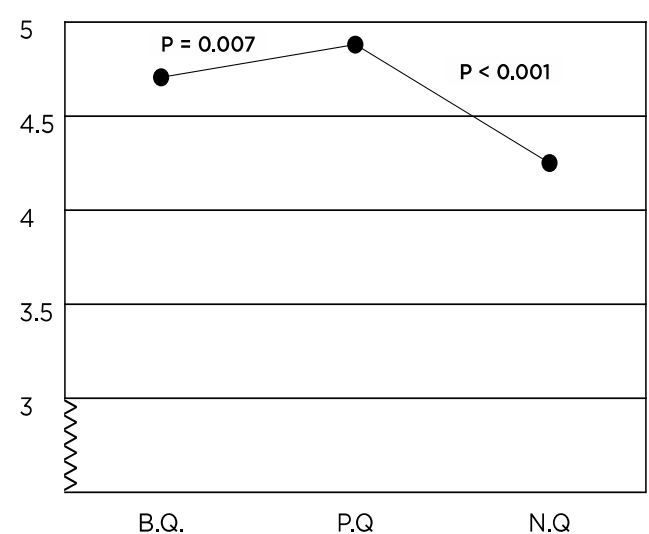

Figure 6. Mean effect of valence on touch from hedonic / emotional brands.

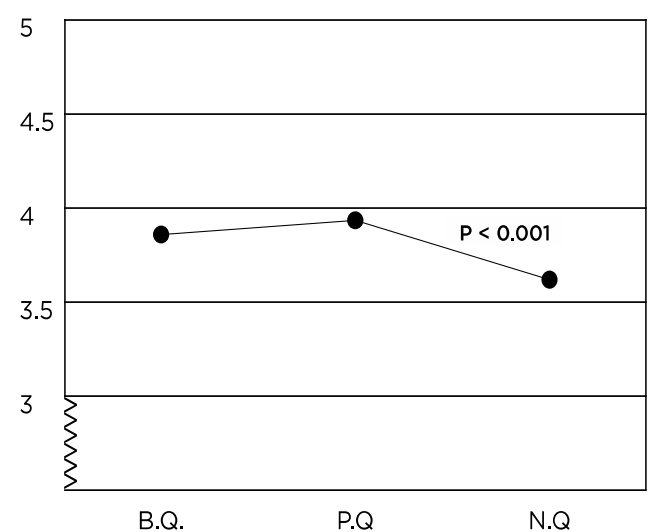

Figure 8. Mean effect of valence on taste from hedonic / emotional brands. 


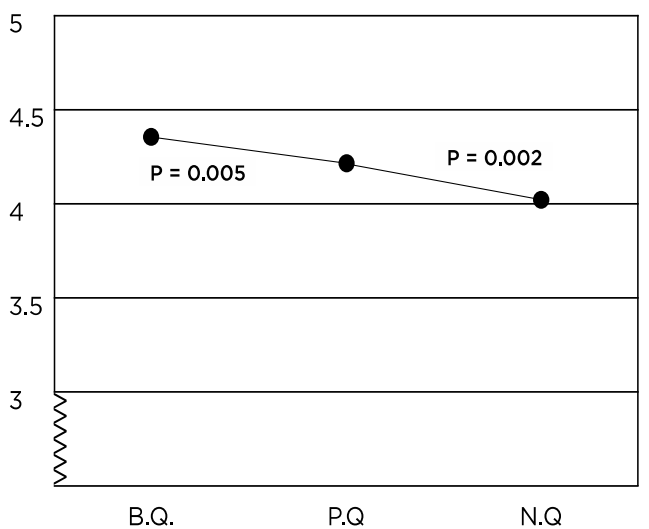

Figure 9. Mean effect of valence on sound from utilitarian / rational brands.

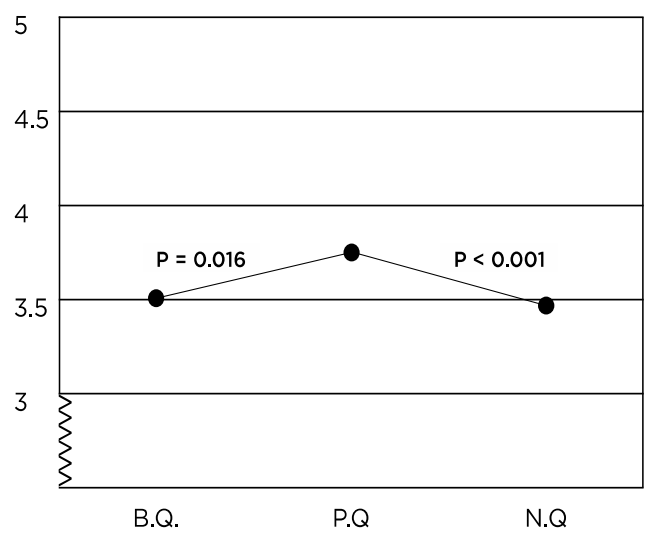

Figure 11. Mean effect of valence on smell from utilitarian / rational brands.

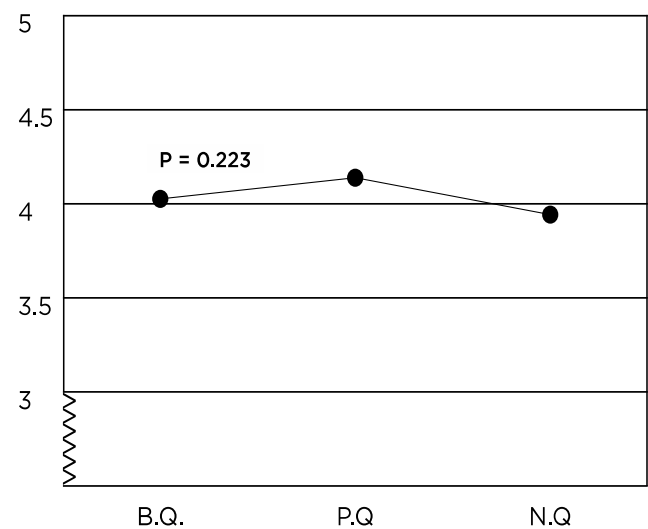

Figure 10. Mean effect of valence on sound from hedonic / emotional brands.

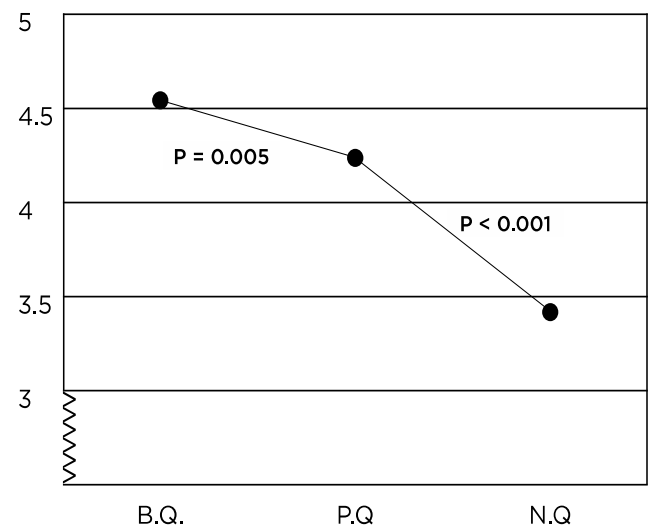

Figure 12. Mean effect of valence on smell from hedonic / emotional brands.

\section{Discussion}

Findings from the current pilot study, an experimental design that crossed valence with six branded products, indicate that the mean effect of valence from all senses for utilitarian/rational brands have registered a highly significant statistical difference between the baseline question, positive and negative reinforcement. Surprisingly, this result is different from the mean effect of valence from all senses for hedonic/emotional brands. Participant response from all five senses did not become more positive when a positive emotional eWOM opinion from a friend was posted online.

Branding is about building lasting value, delighting and providing pleasurable experience for customers (Neumeier, 2007, p. 19). It could be argued that almost by default, hedonic/emotional brands are embedded with emotional, delightful and pleasurable value for the customer. They do not have to work as hard as utilitarian/rational brands in building value. Yet this result 
contends that emotional brands may have to "work harder" than rational ones within social media in order to capture positive valence. There was no positive reinforcement from all five senses found in three emotional brands combined and only three individual senses registered highly statistical differences. Unexpectedly, four senses registered highly statistical difference in three rational brands combined.

The apparent effectiveness of the relationships between rational brands, the senses and social media may have theoretical and managerial implications. Potentially, brand loyalty for these brands may be less impacted, perhaps attributed to personal opinion being secure due to a high degree of product involvement (Wu \& Wang, 2011). It could also be argued that the relationships between emotional brands, the senses and social media are less effective. Participants were less secure with negative opinion indicating that emotional brands may have the potential to elicit greater negative emotions ( $\mathrm{Wu} \&$ Wang, 2011). This result did not fully support the theoretical implication that hedonic/emotional brands are more likely to elicit greater sensory brand appeals through eWOM within social media. Consequently brand loyalty may be more impacted for emotional brands. Key elements have emerged from these results, suggesting that managerial strategies should more deeply consider emotional and subjective capabilities of the customer, which in turn may enable them to stay competitive in the shifting landscape of humanistic branding.

Sight and smell have registered highly significant statistical difference between the baseline question, positive and negative reinforcement for both utilitarian/rational brands and hedonic/emotional brands. The result for smell (hedonic/emotional) is unusual in that rather than the numbers going up with positive reinforcement they went down (Figure 12). This may be due to the mix of brands being examined. A Nike shoe may hold latent emotional memory with regard to smell, but Sony headphones may not. The Versace fragrance should have offered a strong positive and negative result, as it is a brand associated with smell. Perhaps the participants were not influenced by this particular fragrance or changed their mind with the positive question after a focus group discussion, which noted that for some, fragrance has the potential to evoke a headache rather than romance. Despite this, the sight and smell results cast a similar light on Lindstrom's assertions that sight and smell are the senses most likely to be activated when customers access memorable brand experience (Lindstrom, 2005, p. 69). This raises the notion that perhaps both offline and online branding scenarios may experience similar complications when accessing deeply embedded emotional memories and designing explicit or implicit ideas for the five senses.

The was additional evidence in the results that some other senses (hedonic/emotional brands: touch, utilitarian/rational brands: taste and sound) registered highly significant statistical difference. This suggests that the mix of hedonic/emotional products (Nike shoe, Sony headphones and Versace fragrance), are less applicable to the taste and sound senses and that the utilitarian/rational products (Wilcox potatoes, Raid flyspray and Rapid stapler) are less applicable to the touch sense. Notwithstanding subjectivity, it should be noted that one does not 
eat a Nike shoe, Sony headphones and Versace fragrance, but people do touch utilitarian/rational products. Perhaps the reason touch is less implicated is because nested in these products are less positive usage applications.

Subjectivity has a role to play with all of the results, but defining subjectivity in relation to the five senses is difficult, as exemplified by Nagel's theories (Nagel, 1995, p. 47). The described experience within eWOM may manifest as a response correction through the five senses. These corrections may be influenced by subjectivity, especially in cases of limited brand experience. Without experience it is more difficult for a customer to form a view, and in this instance they may seek the opinion of others (Harden \& Heyman, 2009, p. 98; Lepkowska-White, 2013; Vachon, 2011).

\section{Limitations}

Despite the results depicting highly statistical differences, the small sample size $(\mathrm{N}=27)$ and the sampling technique (convenience sample) may expose lack of confidence in the findings. Therefore, in generalising the results there should be caution. Future studies may be designed to involve larger groups, which could be achieved through utilizing the snowballing method in social media once the parameters of the sample have been established (Frost, 2011, p. 129).

The responses being measured by the questionnaire were subjective and therefore a limited picture of the issue may have been revealed (Creswell, 1994, p. 119; Crouch and Pearce, 2012, p. 131). The sound results were not as expected, especially since the brand related to a specific sense. The expectation was that the positive or negative valence effects from eWOM may have impacted on this hedonic/emotional brand. One possible explanation for this was that the headphones in question were not state of the art headphones, but rather quite ordinary. Future studies could remedy this by testing with stronger experiment stimuli (Chiou et al. 2013). The other explanation possibly lies in the examination of the other emotional brands grouped with the headphones (Nike shoes and Versace fragrance). These two brands may have offset the result because sound is less associated with these types of brands. The brand loyalty aspect of the study should be strengthened. This requires an additional or better question to connect sensory value and loyalty as manifested by eWOM. Other limitations include lack of ethnic diversity, with future studies designed to involve more diversity.

\section{Conclusions}

As contested, the five senses form part of the value chain for a customer in social media. There is room for business to access information about the role the five senses play in accessing emotional memory through eWOM interactions, and the effect this has on brand loyalty. Now more than ever, brand strategists would be well advised to understand the symbiotic relationships that exist between human sensory value and social media interaction. 


\section{Appendix}

A1. Table 1. Participant Groups

\begin{tabular}{llcl}
\hline Group & Age sample size & Total & Ethnicity \\
\hline $\begin{array}{l}\text { Student group } \\
\text { Architecture }\end{array}$ & $18-25(5$ male, 4 female $)$ & 9 & European \\
Communications & & \\
Commerce & & \\
Humanities & & \\
Law &
\end{tabular}

Designer group 28 - 50 (7 male, 2 female) 9 European

Web / Interactive

Graphic / Brand

Illustration

Fashion

Product

Customer group $30-55$ (4 male, 5 female) $9 \quad$ European

Marketing

Administration

Law

Government

Total

18 - 55 (16 male, 11 female)

27 
Vol. 2, No. 2

Saris: Sensory Branding: A Pilot Study of the Effect of Sensory...

A2. Figure13. Questionnaire Design

1. What is this brand/product? How would you describe this brand by sight, sound, touch, taste and smell (please fill in line no. 1).

2. In your opinion this is the best (product) brand. You post a picture of (product made into something, or you interacting with the brand/product), comments from your friends validate your opinion. How would you describe this brand by sight, sound, touch, taste and smell (please fill in line no. 2).

3. Comments from your friends about this same post are negative. This makes you doubt your opinion. How would you describe ... (line no. 3).

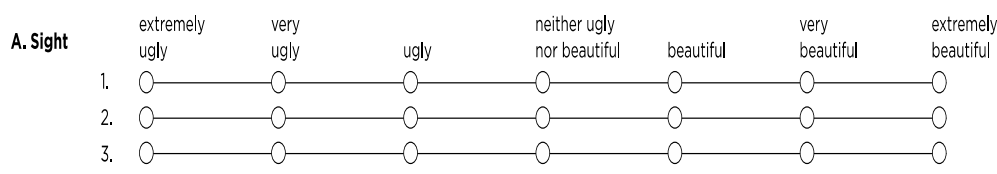

B. Touch extremely very neither rough $\quad$ very extremely

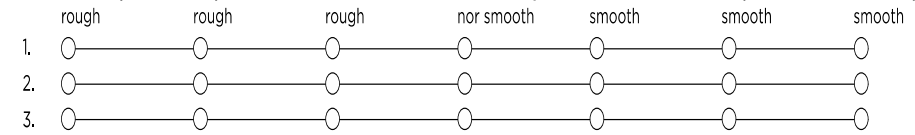

C. Taste extremely very $\quad$ neither distasteful $\quad$ very extremely
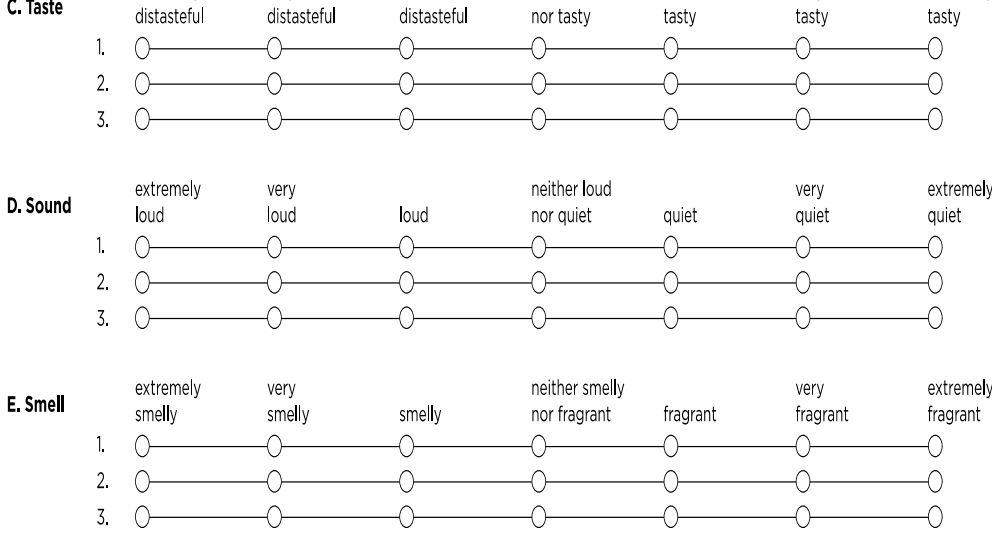


\section{References}

Blackett, T. (2003). What is a brand?. In Clifton, R., Simmons, J., Ahmed, S., Allen, T., Anholt, S., Bahr Thompson, A., Barwise, P., Blackett. T., Bowker, D., Brymer, C., Doane, D., Faulkner, K., Feldwick, P., Hilton, S., Lindemann, J., Poulter, A., \& Smith, S. Brands and branding: Economist books pp. 13-26. London, GBR: Profile books.

Brown, E. (2012). Working the crowd: Social media marketing for business ( $2^{\text {nd }}$ Edn.). Swindon, GBR: British Informatics Society. 2012.

Briefer, E. F., Maigrot, A-L., Mandel, R., Freymond, S. B., Bachmann, I., \& Hillmann, E. (2015). Segregation of information about emotional arousal and valence in horse whinnies. Scientific Reports 4(9989). doi:10.1038/srep09989.

Chiou, J., Hsu, A. \& Hsieh, C. (2013). How negative online information affects customers' brand evaluation: The moderating effects of brand attachment and source credibility. Online information review 37(6) pp. 910-926.

Clark, K. A. (2004). Brandscendence: Three essential elements of enduring brands. Chicago, IL: Dearborn Trade, A Kaplan Professional Company.

Creswell, J. (1994). Research design: Qualitative \& quantitative approaches. London, England: Sage.

Crouch, C., \& Pearce, J. (2012). Doing research in design. London, England: Berg.

Dooley, R. (2011) Brainfluence: 100 ways to persuade and convince consumers with neuromarketing. Hoboken, NJ: John Wiley \& Sons.

Frost, N. (2011). Qualitative research methods in psychology. Berkshire, GBR: McGraw-Hill Education.

Gerson, R. (1998). Beyond customer service: Keeping customers for life. Boston, MA: Course Technology Crisp.

Gobé, M. (2009). Emotional branding: The new paradigm for connecting brands to people. New York, NY: Allworth Press.

Goody, J. (2002). The anthropology of the senses and sensations. La Ricerca Folklorica, 45(0), pp. 17-28.

Guzman, F., \& Iglesias, O. (2012). The multi-sensory and multi-experiential brand challenge. In: Guzman, F. \& Iglesias, O. (Ed.), Challenges facing brand managers today pp. 388-390. UK: Emerald Insight.

Harden, L., \& Heyman, B. (2009). Digital engagement: Internet marketing that captures customers and builds intense brand loyalty. Saranac Lake, NY, USA: Amacom Books.

Ha, H-Y. (2004). Factors influencing consumer perceptions of brand trust online. The Journal of Product and Brand Management, 13(4), pp. 329-342.

Jung, L. H. \& Soo, K. M. (2012). The effect of brand experience on brand relationship quality. Academy of Marketing Studies Journal 16(1), pp. 87-98.

Lepkowska-White, E. (2013). Are they listening? Designing online recommendations for today's consumers. Journal of Research in Interactive Marketing. 7(3), pp. 182-200.

Lin, T. M., Lu, K., \& Wu, J. (2012). The effects of visual information in eWOM communication. Journal of Research in Interactive Marketing, 6(1), pp. 7-26.

Lindstrom, M. (2005). Brand Sense: Build powerful brands through touch, taste, smell, sight and sound. London, England: Kogan Page.

Morillo, C. (1990). The Reward Event and Motivation. Journal of Philosophy 87(4), pp. 169-186.

Murray, B. H. (2003). Defending the brand: Aggressive strategies for protecting your brand in the online arena. New York, NY: Amacom Books. 
Nagel, T. (1995). Other minds: Critical essays, 1969-1994. New York, NY: Oxford University Press.

Neumeier, M. (2007). Zag: The number-one strategy of high-performance brands. Berkeley, CA: New Riders.

Oatway, J. (2012). Mastering story, community and influence: How to use social media to become a social leader. Hoboken, NJ: John Wiley \& Sons.

Peters, T. (2003). Re-imagine! Business excellence in a disruptive age. London, England: Dorling Kindersley.

Post, K. (2004). Brain tattoos: Creating unique brands that stick in your customers' minds. Saranac Lake, NY, USA: Amacom Books.

Powell, G., Groves, S., \& Dimos, J. (2011). ROI of social media: How to improve the return on your social marketing investment. Hoboken, NJ, USA: Wiley \& Sons.

Pradeep, A. K., and Meerman, D. (2010). Buying brain: Secrets for selling to the subconscious mind. Hoboken, NJ: John Wiley \& Sons.

Schultz, D. E., \& James, P. (2013). Social media's slippery slope: challenges, opportunities and future research directions. Journal of Research in Interactive Marketing. 7(2), pp. 86-99.

Siegel, S. (2013). The contents of perception. In E. N. Zalta (Edn.) The Stanford encyclopedia of philosophy. Retrieved from http://goo.gl/TCzBEV. [Accessed: 3 September 2014].

Yohn, D. L. (2013). What great brands do: The seven brand-building principles that separate the best from the rest. Somerset, NJ: John Wiley \& Sons.

Vachon, F (2011). Can online decision aids support non-cognitive web shopping approaches? International Journal of Business and Management 6(10), pp. 16-27.

Van Gulick, R. (2014). Consciousness. In E. N. Zalta (Edn.) The Stanford encyclopedia of philosophy. Retrieved from http://plato.stanford.edu/entries/ consciousness/

Verhagen T., Boter J., \& Adelaar T. (2010). The effect of product type on consumer preferences for website content elements: An empirical study. Journal of Computer-Mediated Communication, 16(1), pp. 139-70.

Wu, P. C., \& Wang, Y-C. (2011). The influences of electronic word-of-mouth message appeal and message source credibility on brand attitude. Asia Pacific Journal of Marketing and Logistics 23(4), pp. 448-472. 